\title{
Assistência de enfermagem humanizada à criança hospitalizada
}

\author{
Humanized nursing care to hospitalized child
}

\section{Cuidados de enfermería humanizada a los niños hospitalizados}

\begin{abstract}
Resumo: Desde o século XX, vemos a preocupação sobre humanização na área da saúde. Logo as instituições tem se preocupado com assistência humanizada nos tratamentos e em espaços diferenciados no ambiente hospitalar. Com relação a criança, pode parecer complexo, por envolver a relação com o acompanhante, onde a comunicação se dá por relações de afeto. O enfermeiro deve atuar na interação com paciente e família, tendo a mão o uso de brinquedo terapêutico que é uma técnica baseada nos princípios da ludoterapia, adaptado para aliviar ou diminuir a ansiedade na criança, que esteja ou não hospitalizada, gerada por experiências para sua idade. O objetivo foi apresentar à equipe de enfermagem a importância do cuidado humanizado com a criança hospitalizada. O estudo caracteriza-se em pesquisa bibliográfica em revistas e banco de dados eletrônicos como BIREME, LILACS, MEDILINE e SciELO. Concluiu-se que a enfermagem tem uma real importância do cuidado humanizado com o menor hospitalizado, melhorando a maneira peculiar de conviver com a situação da doença.
\end{abstract}

Descritores: Humanização, Criança, Brinquedo Terapêutico, Enfermagem.

Abstract: Since the twentieth century, we see the concern on humanization in health care. Thus, the institutions have been preoccupied with humanized treatments and different spaces in the hospital. With respect to children may seem complex, it involves the relationship with the companion, where communication takes place through relationships of affection. The nurse must act in interaction with patient and family, taking her hand the use of therapeutic play, which is a technique based on the principles of play therapy, adapted to relieve or lessen the anxiety, or who is not hospitalized, generated by their experiences to age. The aim was to present the nursing staff the importance of humane care to the hospitalized child. The study features in literature in journals and electronic databases such as BIREME, LILACS, MEDILINE and SciELO. It was concluded that nursing has a real importance of humanized care at the lowest hospital, improving the peculiar way of living with the disease situation.

Descriptors: Humanization, Child, Toy Therapeutic, Nursing.

Resumen: Desde el siglo XX, vemos la preocupación acerca de la humanización en la atención de la salud. Por lo tanto, las instituciones se han preocupado por tratamientos humanizado y diferentes espacios en el hospital. Con respecto a los niños puede parecer complejo, que implica la relación con el compañero, donde la comunicación se lleva a cabo a través de relaciones de afecto. La enfermera debe actuar en interacción con el paciente y la familia, teniendo en su mano el uso del juego terapéutico, que es una técnica basada en los principios de la terapia de juego, adaptado a aliviar o disminuir la ansiedad, o que no está hospitalizado, generado por sus experiencias a edad. El objetivo fue presentar el personal de enfermería la importancia de la asistencia humanitaria a los niños hospitalizados. El estudio de las características de la literatura en revistas y bases de datos electrónicas como BIREME, LILACS, MEDILINE y SciELO. Se concluyó que la enfermería tiene una importancia real de la atención humanizada a los mejores hospitales, la mejora de la peculiar forma de vivir con la situación de la enfermedad.

Descriptores: Humanización, Niño, Juguete Terapéutico, Enfermería. 


\section{Introdução}

A humanização na área da saúde entrou em discussão pelo "Movimento da Reforma Sanitária", ocorrido nos anos 70 e 80 do século $X X$, deu inicio ao movimento sobre humanização na área da saúde. Iniciaram os questionamentos acerca do modelo assistencial vigente, centrado no médico, no estudo da biologia e nas práticas curativas ${ }^{1}$.

As instituições voltadas para a assistência às crianças surgiram como pioneiras na implantação do conceito de humanização no tratamento e concepção dos espaços. Isso ocorreu como resultado da percepção do atendimento à criança, que aparece como algo complexo, pois envolve a relação com o acompanhante, onde a comunicação se dá por relações de afeto. A imagem do hospital como local de dor, juntamente com o medo natural que uma criança tem de ambientes estranhos, permanece na memória de muitos $^{2}$.

O serviço de saúde deve ter como eixo central a humanização e os aspectos subjetivos da condição humana, pois a interação dos conhecimentos técnica e científica com os aspectos afetivos, sociais, culturais e éticos na relação entre o profissional e o paciente garante maior eficácia do serviço ${ }^{3}$.

A criança é fruto do ambiente que vive, ou seja, sua família irá influenciar suas experiências infantis e todo seu processo de socialização. O trabalho de enfermagem que cuida de crianças deve respeitar as diferenças culturais existentes dentro dos grupos sociais, respeitando-se ao estilo de cuidar da mãe que foi herdado culturalmente ${ }^{4}$.

O brincar é a atividade mais importante da vida da criança e é principal para seu desenvolvimento motor, emocional, mental e social. É a forma pela qual ela se comunica com o meio em que vive e expressa ativamente seus sentimentos, ansiedades e frustrações ${ }^{5}$.

Um trabalho de humanização em pediatria visa à integração de diversas áreas da saúde, envolvendo: familiares; criança e adolescentes hospitalizados, logo as atividades recreativas e educacionais, visam ações humanística no atendimento ao paciente valorizando aspecto social e efetivo. A humanização entre a equipe de saúde e a família, pode favorecer uma melhor identificação da criança. É necessária uma enfermagem atuante, priorize o aspecto educativo da assistência e que tanto a família como a equipe de enfermagem interagem e se comuniquem de uma forma necessária ${ }^{6}$.

A hospitalização vem e provoca alterações nas relações da criança e família, pois impõe a estes um ambiente diferente com regras desconhecidas, podendo gerar medo ansiedade em ambas as partes. A criança hospitalizada é mais vulnerável a ocorrências adversas, a um evento indesejável, ações violentas, e estes tem necessidade de supervisão direta. O menor não possui capacidade de decidir sobre suas ações que ocorre durante a assistência à saúde, consequentemente necessita de cuidado direto ${ }^{6}$.

A doença da criança faz com que a família também se sinta doente e até mesmo culpada pelo acontecimento, pois a doença é um fator de desajustamento que provoca, precipita ou agrava desequilíbrios psicoemocionais na criança e na família”.

A enfermagem tem utilizado o brinquedo terapêutico, como uma atividade não direta de brincar, cuja finalidade é permitir a ela a compreensão dos sentimentos e das reações emocionais manifestados pelas crianças, o significado que têm para elas os procedimentos dolorosos, assim como prepará-las para procedimentos desagradáveis, entre os quais a cirurgia ${ }^{8}$.

Um hospital escola em Minas Gerais, apresentou um programa de humanização na assistência hospitalar que reuniu projetos relacionados com o movimento de humanizar a assistência hospitalar, estes projetos abrangem as políticas de humanização e programas específicos para pediatria, com o nome de ABRAÇARTE visando a humanização do atendimento à criança hospitalizada 9 .

O uso do brinquedo terapêutico é como uma técnica baseada nos princípios da ludoterapia, adaptado para aliviar ou diminuir a ansiedade na criança, que esteja ou não hospitalizada, gerada por experiências para sua idade $^{10}$.

É comum os hospitais pediátricos manterem programas de recreação que ajudam a tornar o período de hospitalização menos estressante e ameaçadora, objetivando desenvolver a integração da equipe multidisciplinar e a família, valorizando aspectos sociais e afetivos, com atividades recreativas e educacionais, 
humanizando as relações interpessoais a da ambientação da equipe de enfermagem. A humanização entre a equipe da saúde e a família, pode favorecer uma melhor identificação da criança. É necessária uma atuação efetiva da enfermagem, onde priorize o aspecto educativo da assistência para que a família e a equipe de enfermagem possam interagir e se comunicar de uma forma compreensiva ${ }^{11}$.

\section{Objetivo}

O objetivo deste trabalho foi apresentar à equipe de enfermagem a importância do cuidado humanizado com a criança hospitalizada.

A relevância do estudo está em trazer para o meio acadêmico e profissional discussões e debates sobre uma prática pedagógica e profissional mais humanizada, para o exercício da humanização no processo ensino aprendizagem e laboral, entendendo que este é o primeiro passo para um cuidado humanizado.

\section{Material e Método}

Tratou-se de revisão bibliográfica, que descreve trabalhos der autores enfermeiros que descrevem sobre humanização no cuidado do menor hospitalizado, os métodos do uso deste como o brinquedo e atividades recreativas.

As fontes utilizadas para esta pesquisa foram artigos científicos publicados no período de 2000 a 2010. O que norteou a buscados artigos é o que caracterizam sua práxis em relação aos usuários que a literatura tem objetivo de demonstrar pesquisas com conhecimento e respaldo científico. As fontes foram selecionadas de acordo com o tema de humanização no cuidado da criança hospitalizada, as literaturas consultadas foram revistas que apresentaram o tema referido, e fontes de bases de dados eletrônicos como: Bireme, Lilacs, Medline e Scielo; utilizando os descritores como: humanização, brinquedo terapêutico, criança hospitalizada.

\section{Resultados e Discussão}

A palavra hospital origina-se do latim hospitalis, que significa ser hospitaleiro, acolhedor, adjetivo derivado de hospes, que se refere à hóspede, estrangeiro, conviva, viajante, aquele que dá agasalho, que hospeda. No início da era cristã, a terminologia mais utilizada relacionava-se com o grego e o latim, sendo que hospital tem hoje a mesma concepção de nosocomium, lugar dos doentes, asilo dos enfermos e nosodochium, que significa recepção de doentes ${ }^{12}$.

O brincar é um fenômeno natural e universal do homem, e acompanha-o em sua evolução histórica e atual. O valor dessa atividade no desenvolvimento da criança tem sido cada vez mais reconhecido. São inúmeras as atividades e brincadeiras que podem ser utilizadas com função terapêutica, uma delas é utilizar os próprios objetos médicos, que quando manipulados, deixam de serem assustadores e passam a ser brinquedos. Com eles a criança pode brincar de médica, expressando assim seu medo e ansiedade e o hoteleiro hospitalar pode valorizar a brinquedoteca hospitalar como fator de humanização e hospitalidade ${ }^{13}$.

Muitas crianças hospitalizadas não conseguem verbalizar seus desejos e necessidades. Na maioria das vezes, quando internadas no hospital, passam por um processo de sofrimento físico, o qual se amplia por um mal estar psicológico, o que toma as crianças mais sensíveis e susceptíveis a sensações negativas. É importante, portanto, reconhecer sua capacidade de se exprimirem através de atividades lúdicas ${ }^{13}$.

O retorno da criança ao seu universo simbólico pelo lúdico no contexto de internação hospitalar é visto como relevante na promoção da adaptação da criança ao meio hospitalar, funcionando como um instrumento de comunicação que facilita o ajustamento emocional a um contexto não familiar. Descontando a predominância do combate à doença em si, os dados desses estudos ampliam consideravelmente a óptica da recuperação e privilegiam um espaço que favorece a criança expressar de forma simbólica seu sofrimento, ao mesmo tempo em que representa e vivência o que tem de mais saudável em si, seu apego à vida, sua alegria em brincar, em desenhar, em produzir algo de forma prazerosa e espontânea ${ }^{13}$. 
A criança vem à desperta nos adultos dois tipos de sentimentos antagônicos: ela é sentida como aquele ser maravilhoso que encanta, transmite alegria, pureza e esperança e por outro, pode induzir irritação e agressividade, na medida em que chora, grita, briga, recusa-se a comer, a tomar banho e a obedecer, tornando-se desagradável. 0 ser humano, essencialmente frágil e desprotegido no início de sua vida, com certeza morreria de fome ou de frio se fosse deixado à própria sorte ${ }^{14}$.

O ambiente hospitalar sugere estranheza e ameaça, lugar onde as regras técnicas devem se sobrepuser ao comportamento espontâneo da vida diária. O problema se agrava, quando se trata da hospitalização de crianças $A$ esses elementos estressantes se contrapõe - movimento de buscar humanizar a assistência hospitalar. Em particular, para o ambiente pediátrico, 0 lúdico, as brincadeiras, tornam-se instrumentos fundamentais para reduzir a tensão e a ansiedade da criança hospitalizada ${ }^{15}$.

O enfermeiro é o profissional da equipe multidisciplinar que permanece mais tempo junto ao paciente, devendo desempenhar o papel de orientador quanto ao preparo psicossomático, assistindo ao ser humano e prestando o cuidado individualizado ${ }^{15}$.

O brinquedo além de ser uma forma de lidar com as adversidades da hospitalização é uma ferramenta para alegrar o ambiente, tantas vezes frio e sem vida, bem como uma maneira de aliviar as sensações desagradáveis da hospitalização ao favorecer a comunicação, humanizando consequentemente o cenário hospitalar ${ }^{12}$.

A brincadeira, portanto é o dispositivo do qual a criança se utiliza como forma de autoterapia constituindo-se na base da psicoterapia infantil, que é a ludoterapia, uma vez que o brinquedo ao influir tanto no aspecto cognitivo da criança quanto no aspecto emocional transforma-se num potencializador do desenvolvimento e da capacidade adaptativa do ser criança modificando estratégias para lidar com as emoções insurgidas durante a hospitalização ${ }^{16}$.

A criança hospitalizada vivência uma experiência que poderá causar problemas variados em seu desenvolvimento emocional, sendo negativas ou positivas afastando de seu ambiente domiciliar, de seus brinquedos e até mesmo de pessoas que tenham grande valor em sua vida, portanto poderá ocorrer uma mudança nesse período hospitalizado como a mudança em seu comportamento ${ }^{17}$.

Questiona-se sobre até que ponto a formação dos trabalhadores em saúde, especificamente em enfermagem, vem dando conta de propiciar o desenvolvimento de competências que favoreçam uma atuação que contemple o homem em sua integralidade, complexidade e singularidade, valorização essa fundamental para a constituição de um fazer humano em saúde ${ }^{18}$.

A humanização do atendimento a criança hospitalizada e da sua família é o que faz a conferencia e o reconhecimento de um trabalho nacional de cuidado humanizado, onde acarreta os esforços continuo do serviço de enfermagem para a continuidade deste trabalho em equipe ${ }^{19}$.

Sendo assim a equipe multiprofissional tem que saber trabalhar esse lado e interá-la novamente ao seu mundo de vivência, ajudando a preencher tudo aquilo que ficou vago naquele período ${ }^{20}$.

O ensino de enfermagem vem buscando a capacitar os profissionais da saúde, o aperfeiçoamento no cuidado ao ser humano-cliente, através de tecnologias e procedimentos que promovam a saúde, fazendo a prevenção das doenças, através de habilidades e atendimentos às necessidades do outro, sendo assim sua formação deve estar igualmente voltada às necessidades do sujeito enquanto ser humano, e não visando só a técnica, mas sim a excelência do cuidado prestado. Trazendo para o cuidador sentimento de prazer e satisfação, havendo assim o cuidado com o outro e também com si mesmo ${ }^{20}$.

O processo de internação pode gerar a criança/adolescente e a sua família sentimentos de tristeza podendo relacionar com a dor e a cura. Os pais têm uma participação importante no cuidado de seus filhos adoentados, e para que essa assistência de enfermagem seja eficaz e tenha qualidade tanto à criança, adolescente e até de seus familiares é necessário que o profissional da saúde faça um conceito das atitudes tomadas e realizadas perante aqueles que iram receber o cuidado ${ }^{7}$.

Portanto a partir da aprovação do estatuto da criança e do adolescente, para que obtenha resultados satisfatórios as instituições de saúde são obrigadas a manter uma 
pessoa da família que acompanhe o mesmo durante o período de internação ${ }^{7}$.

\section{Conclusão}

Como acadêmica de Enfermagem, compreendo a importância do espaço lúdico e assistência humanizada no âmbito hospitalar como importante fator de humanização neste setor. Quando um profissional enfermeiro observa os benefícios de uma assistência humanizada, para o menor, a família, as brincadeiras se portaram como elemento importante para se distraírem, fazer novos amigos e para reduzir a tensão decorrente da situação de hospitalização.

Outro aspecto importante é a repercussão do brincar para os familiares e acompanhantes dos pacientes. Alguns pais relatam que as crianças quando se encontram internadas sentem-se falta das atividades do seu cotidiano, por isso, se mostram satisfeitos e tranquilos quando encontra no hospital um espaço que não priva a criança do brincar e das atividades próprias de sua idade. Percebe-se que o brincar tem aproximado os pais, acompanhantes e equipe de saúde de seus filhos e pacientes, enriquecendo e fortalecendo os laços afetivos.

Os pais podem ser incentivados a brincar com os seus filhos e isso tende a auxiliar de forma mais global, no processo de enfrentamento do período de hospitalização.

As equipes de enfermagem ao ver o sorriso da criança e seu envolvimento nas atividades realizadas, sem dúvida, são um dos maiores retornos imediatos de abraçar a humanização como importante cuidado. Todos da equipe de enfermagem podem perceber os efeitos no sentido de maior bem-estar dos pacientes.

$\mathrm{Na}$ assistência no período do estagio em pediatria foi possível usufruir e conhecer os principais ingredientes para o sucesso que é o compromisso da equipe de enfermagem de trazer os conhecimentos da formação acadêmica e ética pela sensação de estar contribuindo para amenizar a estadia da criança no ambiente estranho e tenso do hospital.

Finaliza-se o trabalho ao concluir que o objetivo diante proposto foi evidenciado ao apresentar aqui a real importância dos cuidados humanizados com o menor hospitalizado.

\section{Referências}

1. Rizzotto MLF. As políticas de saúde e a humanização da assistência. Revista Brasileira de Enfermagem. 2002; 55(2):196-99.

2. Brasil. Ministério da Saúde. Núcleo técnico da política nacional de humanização. Humaniza SUS política nacional de humanização. Textos Básicos de saúde. Brasília: 2003.

3. Bergan C, Santos COM, Bursztyn I. Humanização nos espaços hospitalares pediátricos: a qualidade do espaço construído e sua influência na recreação da criança hospitalizada. Anais do I Congresso Nacional da Abdeh - IV Seminário de Engenharia Clínica. 2004. Disponível em: <http://bvsms.saúde.gov.br>. Acesso em 15 set 2009.

4. Cabral IE. O estilo de cuidar da mãe e o trabalho da enfermagem. Rev. Enferm. UERJ. 2000; 3(2):189-195.

5. Collet N, Rocha SRMM, Vieira CS, Oliveira BRG. Processo de trabalho da enfermagem na assistência a criança hospitalizada. Disponível em: <http://cacphp.unioeste.br>. Acesso em 27 out 2009.

6. Bazon FVM, Campanelli EC, Blascovi-Assis SM. A importância da humanização profissional no diagnóstico das deficiências. Universidade Presbiteriana Mackenzie. Disponível em: <http://pepsic.bvs-psi.org.br>. Acesso em 15 set 2009.

7. Fernades CNS, Andraus LMS; Munari IDB. O aprendizado do cuidar da família da criança hospitalizada por meio de atividades grupais. Revista Eletrônica de Enfermagem. 2006; 8(1):108-118. Disponível em: <http://www.revistas.ufg.br>. Acesso em 21 out 2009.

8. Castro AS, Silva CV, Ribeiro CA. A vivência do pré escolar no pós-operatório de postectomia. Rev. Latino-Am Enferm. 2004; 797-805.

9. Penido RC, Mata C, Goretti D, Guimarães F, Santos MR, Assunção M, Bambirra N, Matos R, Silva RC, Guimarães W. Programa de Humanização na Assistência Hospitalar do Hospital das Clínicas. Universidade Federal de Minas Gerais. Disponível em: <http://www.prac.ufpb.br>. Acesso em 21 out 2009.

10. Mitre RMA, Gomes RA. A promoção do brincar no contexto da hospitalização infantil como ação de saúde. Rev. Cienc Saúde. 2004; 147-154. 
11. Schatkoski AM, Wegner W, Algeri S, Pedro ENR. Safety and protection for children in hospital. Rev. Latino-Am Enfermagem. 2009; 17(2).

12. Lisboa TC. Breve história dos hospitais. 2002. Disponível em: <http://www.prosaude.org.br>. Acesso em 21 out 2009.

13. Dietz KG, Oliveira VB. Brinquedotecas hospitalares, sua análise em função de critérios de qualidade Bol. São Paulo: Acad. Paul. Psicol. 2008; 28(1).

14. Blanco Del MPP. El niño hospitalizado: características, evaluación y tratamiento. Madrid: Pirâmide. $1995 ; 178$.

15. Carvalho R, Biamchi ERF. Enfermagem em centro cirúrgico e recuperação. São Paulo: Manole. 2007.

16. Collet N, Rocha SMM. Relação entre pais e enfermeiros no cuidado à criança hospitalizada: um ensaio crítico. Rio de Janeiro: Esc. Anna Nery. Rev. Enferm. 2000; 4(1):55-65.
17. Franca APD, Mendes LM. Relacionamento multiprofissional $X$ criança e acompanhante: desafio para a equipe. USP: Rev. Esc. Enf. 2000; 31(3):423-36.

18. Morais GSNO. Brincar na construção de um cuidado integral a criança hospitalizada. Disponível em: <http://www.revistas.ufg.br>. Acesso em 20 mar 2010.

19. Lima EC, Issi HB, Cachafeiro MEH, Hilling MG, Ribeiro NRR. Modelo de cuidado diferenciado de enfermagem a família da criança internada na unidade de terapia intensiva pediátrica. Curitiba: Fam. Saúde Desenv. 2006; 8(2): 168-177.

20. Silva MJP, Gimenes OMPV. Cuidando da saúde. São Paulo: Revista O Mundo da Saúde. 2000; 24(4):307-309. 